\title{
O USO DO PLASMA RICO EM PLAQUETAS NO TRATAMENTO DE ÚLCERAS VENOSAS CRÔNICAS
}

\author{
Alcione Matos de Abreu \\ Beatriz Guitton R. Baptista de Oliveirab \\ Mylena da Cruz Araújoc
}

As úlceras venosas crônicas estão associadas com a hipertensão venosa dos membros inferiores e correspondem a um percentual que varia aproximadamente de $80 \%$ a $90 \%$ das úlceras de perna. Estas permanecem, muitas vezes, abertas por meses ou anos, causando problemas socioeconômicos tanto para o paciente/cliente como para as organizações de saúde e sociedade.,2

Em geral, a úlcera venosa apresenta borda irregular, é superficial no início, mas pode tornar-se profunda, com bordas bem definidas e comumente com exsudato seroso. A dor é sintoma frequente e de intensidade variável, não sendo influenciada pelo tamanho da úlcera; quando presente, a dor piora ao final do dia com a posição ortostática, melhorando com a elevação do membro na altura do coração. ${ }^{3}$

A possibilidade de recuperação das úlceras venosas tem sido um desafio para os profissionais e pesquisadores da área da saúde. Desta forma, há necessidade de tecnologias eficazes para tratamento de úlceras venosas que favoreçam o processo de reparo tecidual de forma segura e efetiva. ${ }^{4}$ Processo este muito complexo que envolve diversos eventos celulares, moleculares e bioquímicos, isto é, depende de inúmeros fatores para que o reparo tecidual ocorra de maneira satisfatória. ${ }^{5} \mathrm{~A}$ resposta que cada indivíduo apresenta a este processo é distinta e depende de fatores externos e internos associados.

Entre as diversas substâncias que podem ser utilizadas no tratamento tópico das úlceras venosas encontra-se o plasma rico em plaquetas (PRP), que consiste em uma concentração autóloga de plaquetas em um pequeno volume de plasma, obtida por centrifugação do sangue total. É considerado uma importante fonte de fatores de crescimento (FC) e de fibrina rica em plaquetas (PRF), que é um concentrado de plaquetas, obtido de uma membrana de fibrina, que possui um alto potencial de regeneração tecidual. ${ }^{6}$

Para Klein, Wagner e Silva ${ }^{6}$, o interesse pelo uso do PRP como biomaterial aumentou na medicina regenerativa, encontrando-se aplicações clínicas em cirurgias oral e maxilofacial, periodontais, ortopédicas e em plástica, além do seu uso no reparo tecidual de feridas crônicas e em queimaduras. Além disso, tem sido considerado um tratamento promissor para as úlceras venosas. ${ }^{4}$

O PRP contém sete FC e três proteínas (fibrina, fibronectina e vitronectina) que atuam como moléculas de adesão celular nos processos de migração epitelial e de formação do tecido conjuntivo. Podem conter também a presença de proteínas osteocondutoras, que atuam na formação óssea e de tecido conectivo. ${ }^{7}$

Os FC ou sinalizadores moleculares estão presentes em diversos tecidos, principalmente quando estão em fase de remodelação ou reparação, apresentando papel fundamental nos processos de proliferação celular, diferenciação, quimiotaxia e formação de matriz extracelular. $^{8}$

Para a promoção da cicatrização das úlceras crônicas, o PRP pode ser utilizado sob forma de gel, spray ou injeção perilesional. 0 tratamento com o PRP potencializa a reepitelização das úlceras crônicas pela ação das proteínas reguladoras do ciclo celular, como a ciclina A e de CDK4. ${ }^{8}$

Inicialmente, o PRP era obtido através de máquinas de plasmaférese e utilizava-se a trombina bovina para sua ativação. 0 interesse em melhorar o custo-benefício para obtenção do PRP criou a necessidade de desenvolver protocolos e o uso de centrífugas comuns para sua obtenção. ${ }^{7}$

Para Maffulli e Del Buono ${ }^{9}$ existem pelo menos três métodos para a obtenção do PRP: 1) aférese (automático), que possibilita a captura de plaquetas pela utilização de filtro descartável; 2) buffy-coat (semiautomático), que permite a separação das plaquetas por centrifugação utilizando kits comerciais (sistemas ACP, GPS II, GPS III, SmartPReP2 etc.; e 3) manual, resultante da centrifugação do sangue total armazenado em tubos contendo anticoagulante. A técnica manual com dupla centrifugação, além de ser a de menor custo, é considerada a mais fácil.

\footnotetext{
${ }^{\text {a }}$ Doutora em Enfermagem pela Universidade Federal Fluminense (UFF), vice-presidente da SOBEENFe e Editora Científica da Revista Enfermagem Atual.

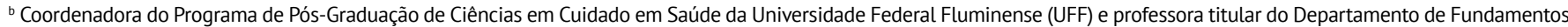
em Enfermagem (MFE) I da Escola de Enfermagem Aurora de Afonso Costa/UFF.

‘ Graduanda em Enfermagem pela Universidade Federal Fluminense (UFF).
} 
Conclui-se que a abordagem terapêutica dos pacientes com úlcera venosa deve ser fundamentada, para a maioria dos casos, no tratamento tópico adequado da úlcera aliado ao uso das terapias compressivas elásticas (meias e ataduras elásticas) e inelásticas (Bota de Unna). ${ }^{10}$

\section{Referências:}

1. SILVA et al. Enfermagem em estomoterapia: cuidados clínicos ao portador de úlcera venosa. Rev Bras Enferm. 2009 nov-dez; 62(6): 889-93.

2. BOSWELL SG et al. Platelet-rich plasma: a milieu of bioactive factors. Arthroscopy. 2012; 28: 429-439.

3. ABBADE LPF, LASTORIA SA. Abordagem de pacientes com úlcera da perna de etiologia venosa. An Bras Dermat. [online]. 2006; 81(6): 509-522.

4. PINTO JMN et al. Application of platelet-rich plasma in the treatment of chronic skin ulcer - Case report. An Bras Dermatol [online]. 2014 [Acesso em 2015 abr 8]; 89(4): 638-640. ISSN 0365- 0596. Disponível em: http://www.scielo.br/pdf/abd/v89n4/0365-0596abd-89-04-0638.pdf.

5. GOULD L et al. Chronic Wound Repair and Healing in Older Adults: Current Status and Future Research. J Amer Geriat Soc. 2009 nov-dez; 63(3): 427-438.

6. KLEIN CP, WAGNER SC, SILVA JB. Obtenção de plasma rico em plaquetas: avaliação do efeito da centrifugação sobre a concentração de plaquetas através da comparação entre protocolos. Rev Bras Bioci. 2011 out-dez; 9(4): 509-513.

7. VENDRAMIN FS et al. Plasma Rico em Plaquetas e fatores de crescimento: Técnica de preparo e utilização em cirurgia plástica. Rev Col Bras Cirur. 2006; 33(1): 24-28.

8. OLSZEWER E, ARROYO E, NAKAMURA F. PRP-Plasma rico em plaquetas. São Paulo, SP: Editora Fapes Books; 2015.

9. MAFFULLI N, DEL BUONO A. Platelet plasma rich products in musculoskeletal medicine: Any evidence? Surg. $2012 ; 10: 148-150$.

10. O'MEARA S, CULLUM NA, NELSON EA, DUMVILLE JC. Compression for venous leg ulcers. Cochrane Data base of Systematic Reviews. 2012; 11. [DOI: 10.1002/14651858.CD000265.pub2] 